\title{
Angiogenic Squamous Dysplasia
}

National Cancer Institute

\section{Source}

National Cancer Institute. Angiogenic Squamous Dysplasia. NCI Thesaurus. Code

C84971.

A morphologic finding indicating the presence of clusters of capillaries projecting into a dysplastic bronchial epithelium. It is considered a pre-invasive lesion. 